\title{
Management of Depression and Anxiety in Primary Care - An Update
}

\author{
Usman Hameed, $M D^{*}$ and Raman Baweja, MD, MS \\ Department of Psychiatry and Behavioral Health, Penn State College of Medicine, Hershey, PA, USA
}

\begin{abstract}
Depression and anxiety are the most common mental health diagnoses in primary care. In this article, we discuss changes in Diagnostic and Statistical Manual of Mental Disorders (DSM) with respect to depressive and anxiety disorders. We also provide a brief overview of assessment of these disorders and associated safety concerns, while maintaining focus on the pharmacologic and non-pharmacologic interventions for the management of depression and anxiety in primary care.

Index Words

Primary care, Mental illness, Psychiatry
\end{abstract}

\section{Introduction}

Depression is a highly prevalent public health concern affecting an estimated 300 million people worldwide in a given year [1]. It is the leading cause of disability worldwide and one of the major causes of completed suicide $[2,3]$. Similarly, anxiety disorders affect a large portion of the population with the lifetime prevalence noted as 10-16\% [4]. In 2001, the estimated number of visits for depression in office-based settings was an alarming 24.5 million, $64 \%$ of these visits were with primary care providers [5].

\section{Changes in Diagnostic and Statistical Manual of Mental Disorders, Fifth Edition (DSM-5)}

In May 2013, the American Psychiatric Association (APA) published DSM-5, which included new diagnosis of disruptive mood dysregulation disorder (DMDD) in children under the category of depressive disorders. This disorder is characterized by chronic irritability and frequent tantrums. Premenstrual dysphoric disorder has been recognized as a separate diagnosis. Persistent depressive disorder represents a consolidation of previously defined chronic major depressive disorder and dysthymic disorder. DSM-5 allows diagnosis of Major Depressive Disorder (MDD) during bereavement based on symptom severity and associated impairment. Additional specifiers for MDD such as: With anxious distress, mixed, melancholic, atypical, mood-congruent/incongruent psychotic features, catatonia, peripartum onset and seasonal pattern, have been included.

The anxiety disorders section from the fourth edition of DSM (DSM-IV) is now separated into three distinct chapters in DSM-5. 1) Anxiety disorders; 2) Obsessive compulsive and related disorders; 3) Trauma and Stressor related disorders.
Anxiety disorders now include selective mutism and separation anxiety disorder. Social Phobia is renamed as social anxiety disorder. Panic attack, is now a specifier for any mental disorder including anxiety, mood, psychotic, substance use and personality disorders. Obsessive compulsive and related disorders now include body dysmorphic disorder, trichotillomania and excoriation disorder and a new category of hoarding disorder. Trauma and Stressor related disorders now include reactive attachment disorder (RAD) and a new category of disinhibited social engagement disorder, formerly called RAD, disinhibited type. Besides Post traumatic stress disorder (PTSD) and acute stress disorder, adjustment disorders are also included in this chapter.

\section{Management}

Some of the screening tools to assist primary care providers are listed in Table 1 . Most of the instruments available online are free and easy to interpret.

The main treatment goal for depression is complete resolution of symptoms. Other treatment objectives are to minimize duration of disease, reduce morbidity and associ-

*Corresponding author: Usman Hameed, MD, Assistant Professor of Psychiatry and Behavioral Health, Department of Psychiatry, Penn State College of Medicine, Penn State Health, 500 University Drive, Hershey, PA 17033, USA

Accepted: April 27, 2021

Published online: April 29, 2021

Citation: Hameed U, Baweja R (2021) Management of Depression and Anxiety in Primary Care - An Update. J Depress Anxiety Disord 3(1):76-79 
Table 1: Depression screening questionnaires.

\begin{tabular}{|l|l|l|l|l|}
\hline Questionnaire & $\begin{array}{l}\text { Number of } \\
\text { items }\end{array}$ & Threshold score & Copyrighted & Indication in population \\
\hline Patient health questionnaire - 9 (PHQ-9) & 9 & 10 of 21 & No & Adults, adolescent (modified) \\
\hline Patient health questionnaire - 2 (PHQ-2) & 2 & 3 of 6 & No & Adults, adolescents \\
\hline Beck depression inventory - II (BDI-II) & 21 & 20 of 63 & Yes & Adults, adolescents \\
\hline Child depression inventory - 2 (CDI-2) Short & 12 & $\begin{array}{l}7-10 \text { of } 24 \text { (Age, gender } \\
\text { based) }\end{array}$ & Yes & Ages: 7-17 years \\
\hline Hospital anxiety \& depression scale & 14 & 8 of 21 & No & Adults 18-80 years \\
\hline Geriatric depression scale - 15 & 15 & 6 of 15 & No & Geriatrics \\
\hline Edinburgh postnatal depression scale & 10 & 10 of 30 & No & Postpartum \\
\hline
\end{tabular}

Table 2: Assessing severity of deperssive disorders (DSM-5).

\begin{tabular}{|l|l|l|l|}
\hline Specifier & Symptoms & Intensity & Impairment \\
\hline Mild & Few, if any, in excess of threshold symptoms & Distressing but manageable & Minor \\
\hline Moderate & In-between mild \& severe & In-between mild \&severe & In-between mild \& severe \\
\hline Severe & Substantially in excess of threshold symptoms & Seriously distressing and unmanageable & Marked \\
\hline
\end{tabular}

ated impairment and prevent recurrence. The principles of management include risk assessment, establishing disease severity and psychosocial support. The severity of illness as described in Table 2, determines treatment options. Mild depression may be closely monitored or managed with supportive care alone. Supportive care includes developing rapport, providing psycho-education regarding condition, and encouraging healthy lifestyle. Psychosocial interventions like cognitive behavior therapy (CBT) and interpersonal therapy (IPT) may be considered in mild to moderate depression. Antidepressant pharmacotherapy is considered in moderate to severe depression.

\section{Pharmacotherapy}

According to American Psychiatric Association's practice guidelines for the Major Depressive Disorder [6], the psychopharmacological treatment of depression is divided into three phases - acute, continuation and maintenance [6]. The acute phase refers to the first 6 to 12 weeks, during which symptoms are treated aggressively aiming at complete resolution. During the continuation phase of 4 to 9 months, the same effective dose of medication is continued. The maintenance phase involves recurrence prevention, given the risk of recurrence approaches $100 \%$ following the $3^{\text {rd }}$ episode. Improvement with medications can be observed as early as the first 1 to 2 weeks of treatment [7], and continues up to 12 weeks. Pharmacotherapy requires at least 4 to 6 weeks to achieve maximum therapeutic effects [8].

Selective serotonin reuptake inhibitors (SSRIs) are the first line treatment for MDD [9]. Recent meta-analysis showed SSRI are superior to placebo in terms of efficacy [10]. The dosing schedule is medication specific. As a general rule, any SSRI may be initiated at the lowest recommended dose and titrated up as clinically indicated, based on tolerability. As an example, the starting dose for fluoxetine is $10-20 \mathrm{mg}$, sertraline is $25-50 \mathrm{mg}$ dose and escitalopram is $5-10 \mathrm{mg}$. Additional treatment options include serotonin norepinephrine reuptake inhibitors (SNRIs) such as venlafaxine, duloxetine, desvenlafaxine; tricyclic antidepressants (TCAs); monoamine oxidase inhibitors (MAOIs); bupropion, mirtazapine, trazodone and nefazodone. Table 3 lists newer medications approved by the Food and Drug Administration (FDA) in the United State of America (USA) in the last decade.

Treatment for anxiety disorders include SSRIs, SNRIs, TCAs, as well as other options including buspirone, benzodiazepines, beta-adrenergic blocking agents, Gabapentin and Pregabalin.

It is important to be aware of adverse effects (AE) of these medications. The FDA issued a black box warning of worsening suicidal behavior in youth and young adults with antidepressant medication. Common AE include gastrointestinal symptoms such as abdominal distress, nausea, diarrhea; headache; disrupted sleep and nightmares; sexual dysfunction, weight gain and bleeding. There are other concerns such as QTc prolongation with Citalopram. TCAs are associated with cardiac arrhythmias, which may be lethal in an overdose. MAOls may result in hypertensive crisis if taken with vasoactive amines or tyramine containing foods. Serotonergic medications may result in Serotonin syndrome (SS), which presents with autonomic instability, agitation, confusion, muscle rigidity, fever, seizures, arrhythmia and even unconsciousness. Symptomatic treatment and the use of benzodiazepines is the treatment of choice for SS. Clinicians should also be familiar with discontinuation syndrome, which often presents as flu-like symptoms associated with abrupt cessation of SSRI or SNRI. Patient education and gradual taper helps prevent these symptoms.

\section{Psychosocial treatments}

CBT is geared toward improved understanding of the interplay between emotions, thoughts, and actions. It is an evidence-based treatment for depression and anxiety. In addition to office-based CBT, computerized CBT has also shown efficacy with depressive and anxiety disorders [11]. Another 
Table 3: Newer antidepressant medication.

\begin{tabular}{|c|c|c|c|c|}
\hline Approval date & Generic (Brand name) & Mechanism of action & Indication & Starting dose (Max) \\
\hline February 2010 & $\begin{array}{l}\text { Trazodone hydrochloride } \\
\text { (Oleptro) }\end{array}$ & $\begin{array}{l}\text { Dual serotonin agonist, serotonin } \\
\text { reuptake inhibitor }\end{array}$ & MDD & $150 \mathrm{mg}$ (375 mg) oral \\
\hline January 2011 & $\begin{array}{l}\text { vilazodone hydrochloride } \\
\text { (Viibryd) }\end{array}$ & SSRI, 5HT1A receptor partial agonist & MDD & $10 \mathrm{mg}(40 \mathrm{mg})$ oral \\
\hline July 2013 & Levomilnacipran (Fetzima) & $\begin{array}{l}\text { Norepinephrine \& serotonin } \\
\text { reuptake inhibitor }\end{array}$ & MDD & $20 \mathrm{mg}(120 \mathrm{mg})$ oral \\
\hline October 2013 & $\begin{array}{l}\text { Vortioxetine (Trintellix/ } \\
\text { Brintellix) }\end{array}$ & Serotonin modulator \& stimulation & MDD & $10 \mathrm{mg}(20 \mathrm{mg})$ oral \\
\hline July 2015 & Brexpiprazole (Rexulti) & Atypical antipsychotic & $\begin{array}{l}\text { Adjunctive for } \\
\text { MDD }\end{array}$ & $\begin{array}{l}0.5 \mathrm{mg}(3 \mathrm{mg}) \\
\text { oral }\end{array}$ \\
\hline March 2019 & $\begin{array}{l}\text { Esketamine nasal spray } \\
\text { (Spravato) }\end{array}$ & NMDA receptor antagonist & $\begin{array}{l}\text { Treatment } \\
\text { resistant } \\
\text { depression }\end{array}$ & $56 \mathrm{mg}(84 \mathrm{mg}$ ) intranasal \\
\hline March 2019 & Brexanolone (Zulresso) & $\begin{array}{l}\text { Allosteric modulator of GABA-A } \\
\text { receptors }\end{array}$ & $\begin{array}{l}\text { Postpartum } \\
\text { depression }\end{array}$ & $\begin{array}{l}30 \mathrm{mcg} / \mathrm{kg} / \mathrm{hr}(90 \mathrm{mcg} / \mathrm{kg} / \\
\mathrm{hr}) \text { intravenous infusion }\end{array}$ \\
\hline
\end{tabular}

Table 4: Risk and protective factors for Suicide [19].

\begin{tabular}{|c|c|}
\hline Risk factors & Protective factors \\
\hline Past suicidal history - personal or family & Support system \\
\hline Access to firearms* & Religiosity and faith \\
\hline Psychiatric diagnoses ${ }^{*}$ & Positive self-esteem \\
\hline Substance misuse ${ }^{*}$ & Effective coping skills \\
\hline Physical illness & $\begin{array}{l}\text { Access to care for } \\
\text { physical, mental \& } \\
\text { substance use disorders }\end{array}$ \\
\hline \multicolumn{2}{|l|}{ Psychosocial features } \\
\hline \multicolumn{2}{|l|}{ Childhood trauma } \\
\hline \multicolumn{2}{|l|}{ Psychological features } \\
\hline $\begin{array}{l}\text { Demographic features: Male, widowed, } \\
\text { elderly, adolescent, Gay, lesbian, or } \\
\text { bisexual orientation }\end{array}$ & \\
\hline
\end{tabular}

*Significant factors

evidence based psychosocial intervention is IPT, which focuses on issues such as role dispute (different expectations in a relationship), role transition (struggle with adjusting to changing responsibilities), unresolved grief and interpersonal difficulties. In a meta-analysis, IPT was considered effective in acute phase of treatment and relapse prevention [12].

Complementary and Alternative Medicine (CAM) such as St. John's Wort, Omega-3 Fatty Acids, S-Adenosyl Methionine have limited evidence for effectiveness in depressive disorders. Kava has been used in anxiety but is associated with hepatotoxicity [13]. Drug-drug interactions are to be considered when using CAM concurrently with medications.

Exercise [14] and phototherapy or bright light therapy [15] has positive outcomes on mood and anxiety symptoms. Neuromodulation treatments such as Transcranial Magnetic Stimulation, Vagal Nerve Stimulation and Electroconvulsive therapy (ECT) are also used for symptoms resistant to traditional therapies.

\section{Other considerations}

For psychotic depression, atypical antipsychotics should be combined with antidepressants and psychosocial therapy, and consider ECT if there is partial or no response. Referral to a mental health clinician for moderate to severe depression and anxiety is a reasonable. Similarly, presence of comorbid conditions and lack of response to trial of several antidepressant medications should prompt a referral to a specialist [16].

\section{Safety Assessment}

Suicide is a serious public health issue due to loss of life with devastating after-effects on the surviving family and community. It is the $2^{\text {nd }}$ leading cause of death in the USA after unintentional injuries among persons 15-34 years of age [17]. According to American Association of Suicidology, there is a life lost to suicide every 12 minutes in the US. There are significant gender differences: Men are 3.4 times more likely to complete suicide compared to women; whereas, women are 3 times more likely to attempt suicide. The rates of suicidal behavior or non-fatal attempts were reported to be significantly higher with 25 attempts for each completed suicide. Unsurprisingly, use of firearms is the most common method of completed suicide, followed by suffocation or hanging and then poisoning [18].

It is almost impossible to predict every suicide attempt. However, there are factors that can assess the risk for suicidal behavior (Table 4). Some risk factors are better correlated with future risk than others. Conversely, there are protective factors as well. For example, rates of suicide attempts and deaths are significantly higher when guns and other lethal means easily available. Reduced access to lethal means can prevent negative outcome. Education of family members regarding importance of restricting access to potentially lethal means cannot be over emphasized.

While conducting a risk assessment, the significance of these factors should be considered more than the absolute number. One such assessment measure is the Columbia Sui- 
cide Severity Rating Scale (www.cssrs.columbia.edu). However, this instrument requires training. In clinical practice, we often use contract for safety during risk assessment, but there is no evidence that such a contract can prevent suicide or suicidal behavior. On the other hand, refusal to contract raises significant safety concerns and is an indication for urgent mental health evaluation.

Levels of care: If there are significant safety concerns, inpatient psychiatric hospitalization is indicated. Individuals may voluntarily request inpatient care. If a person poses a danger to him/herself or others, or is unable to take care of $\mathrm{him} /$ herself, with a reasonable probability of death/serious bodily injury or physical debilitation, without treatment in the next 30 days, they may be subject to involuntary inpatient care. The duration of involuntary commitment varies by jurisdiction. Individuals admitted on voluntary status may be converted to involuntary commitment if they insist on discharge while safety is still a concern.

\section{Conclusion}

In conclusion, depression and anxiety are the most common mental health disorders in primary care and primary care providers manage the majority of these disorders. Therefore, developing a treatment plan, addressing safety and psychosocial and biological factors, is the goal in optimal patient care. Addressing physical and emotional well-being, treating presenting complaint and underlying conditions, providing support services and improving motivation for treatment result are likely to result in better outcomes.

\section{Funding}

None.

\section{Acknowledgments}

Not applicable.

\section{Author Contribution}

All authors contributed to the conception of the article, literature search, write-up and revisions in response to peer reviewers and editorial committee. All authors have read and approved the final article.

\section{Conflict of Interests}

The Authors declare that there is no conflict of interest.

\section{Disclosures}

No financial disclosures to report.

\section{Ethics Approval and Consent to Participate}

Not applicable.

\section{Availability of Data and Materials}

Not applicable.

\section{References}

1. WHO (2017) Media centre.

2. Dumais $A$, Lesage AD, Alda $M$, et al. (2005) Risk factors for suicide completion in major depression: A case-control study of impulsive and aggressive behaviors in men. Am J Psychiatry 162: 2116-2124.

3. Kessler RC, Bromet EJ (2013) The epidemiology of depression across cultures. Annu Rev Public Health 34: 119-138.

4. Somers JM, Goldner EM, Waraich P, et al. (2006) Prevalence and incidence studies of anxiety disorders: A systematic review of the literature. Can J Psychiatry 51: 100-113.

5. Deneke DE, Schultz H, Fluent TE (2014) Screening for depression in the primary care population. Prim Care 41: 399-420.

6. Gelenberg AJ, Freeman MP, Markowitz JC, et al. (2010) Practice guideline for the treatment of patients with major depressive disorder third edition. The American Journal of Psychiatry 167: 1.

7. Taylor MJ, Freemantle N, Geddes JR, et al. (2006) Early onset of selective serotonin reuptake inhibitor antidepressant action: Systematic review and meta-analysis. Arch Gen Psychiatry 63: 1217-1223.

8. Nierenberg AA, Farabaugh AH, Alpert JE, et al. (2000) Timing of onset of antidepressant response with fluoxetine treatment. Am J Psychiatry 157: 1423-1428.

9. Koenig AM, Thase ME (2009) First-line pharmacotherapies for depression - what is the best choice? Pol Arch Med Wewn 119: 478-486.

10. Barth M, Kriston L, Klostermann S, et al. (2016) Efficacy of selective serotonin reuptake inhibitors and adverse events: Meta-regression and mediation analysis of placebo-controlled trials. $\mathrm{Br} \mathrm{J}$ Psychiatry 208: 114-119.

11. Newby JM, Twomey C, Yuan Li SS, et al. (2016) Transdiagnostic computerised cognitive behavioural therapy for depression and anxiety: A systematic review and meta-analysis. J Affect Disord 199: 30-41.

12. Cuijpers $P$, Donker $T$, Weissman MM, et al. (2016) Interpersonal psychotherapy for mental health problems: A comprehensive meta-analysis. Am J Psychiatry 173: 680-687.

13. van der Watt $G$, Laugharne J, Janca A (2008) Complementary and alternative medicine in the treatment of anxiety and depression. Curr Opin Psychiatry 21: 37-42.

14. Carek PJ, Laibstain SE, Carek SM (2011) Exercise for the treatment of depression and anxiety. The Int J Psychiatry Med 41: 15-28.

15. Oldham MA, Ciraulo DA (2014) Bright light therapy for depression: A review of its effects on chronobiology and the autonomic nervous system. Chronobiol Int 31: 305-319.

16. Anthony JS, Baik SY, Bowers BJ, et al. (2010) Conditions that influence a primary care clinician's decision to refer patients for depression care. Rehabil Nurs 35: 113-122.

17. (2015) 10 leading causes of death by age group, United Stated - 2015. National Centre for Injury Prevention and Control, CDC.

18. Drapeau CW (2015) USA Suicide: 2015 Official Final Data. In: McIntosh JL, American Association of Suicidology 2015.

19. Jacobs DG (2003) Practice guideline for the assessment and treatment of patients with suicidal behaviors.

Copyright: ( 2021 Hameed U, et al. This is an open-access article distributed under the terms of the Creative Commons Attribution License, which permits unrestricted use, distribution, and reproduction in any medium, provided the original author and source are credited. 